\title{
MAGNETISM AND ARCHAEOLOGY: MAGNETIC OXIDES IN THE FIRST AMERICAN CIVILIZATION
}

\author{
B.J. EVANS \\ Department of Chemistry, The University of Michigan, Ann Arbor, Michigan 48109, USA
}

\begin{abstract}
Archaeological excavations at sites of the Olmec civilization (1500 to 500 B.C. in present-day Mexico) have unearthed artifacts formed from massive iron oxide ores. Iron oxide ores were ground and shaped into highly polished circular artifacts, called "mirrors", with flat and concave surfaces. These mirrors were employed as body adornments by societal elites and were involved in trade and commodity exchange over large distances. By means of ${ }^{57} \mathrm{Fe}$ Mössbauer spectroscopy, the ore deposits from which material was obtained and the probable dissemination routes of the artifacts have been determined. An unusual bar-shaped artifact with a strong remanent magnetization suggests the existence of a device similar to a compass that predates the Chinese discovery by $10^{3}$ years.
\end{abstract}

\section{Introduction}

The low cognizance level of the general populace for the extent to which magnetism and magnetic materials permeate modern society was documented in an earlier review [1]. There have been few developments since this earlier review that indicate any increase in the awareness of the public for the role that magnetism plays in modern society. It is therefore a delight to the magneticist to learn that magnetic oxides were of intrinsic aesthetic and possibly technical value in one of the earliest American societies. The possibility that a study of the basic magnetic properties of these materials could lead to an elucidation of the role of these materials in such societies is an almost irresistable enticement to interrupt, at least, one's more technical studies with an application of magnetism to archaeology.

In this synopsis, I would like to report some of the salient aspects of our ${ }^{57} \mathrm{Fe}$ Mössbauer studies of archaeological artifacts fashioned from iron ores which were discovered during excavations in southern Mexico [2]. The large, stone, human head monuments of the Gulf Coast "olmecs" have appeared extensively in the popular literature and are, perhaps, familiar to at least a respectable percentage of the general populace. The iron ore artifacts that will be the subject of this discussion were discovered during excavations of these Gulf Coast "olmec" sites in the Mexican states of Veracruz and Tabasco and of some contemporaneous olmecoid sites in the Valley of Oaxaca as indicated on the map in fig. 1.

A large number of archaeologists have been active in the discovery and excavation of olmec and olmecoid sites in Mexico but the significance of this study derives primarily from the work carried out under the auspices of the Museum of Anthropology of the University of Michigan concerning the interrelationships between different cultural centers in Formative Mesoamerica. The term Formative Mesoamerica is used to describe a civilization characterized by agricultural villages in southern Mexico and western Guatemala (fig. 1) and covers the time period between 1500 and 500 B.C.

Even in the first scientifically systematic investigations of the Olmec site at La Venta, Tabasco, highly polished artifacts fashioned from iron ore were discovered (cf. fig. 2). The artifacts have been described as mirrors even though their function is not clear. During several expeditions between 1943 and 1955 at least seven such mirror and mirror fragments were found at the La Venta site [3]. Subsequent investigations established that suitable iron ore sources were more than $100 \mathrm{~km}$ from La Venta. Using petrographic techniques [3], e.g. the petrographic, reflected light microscope and microhardness tests, the minerals in these mirrors were identified as hematite, magnetite, and ilmenite. Only the gross petrologic characteristics of the mirrors were revealed by these measurements and insufficient data were available for the identification of possible source ore sites.

For more than ten years these "mirrors" were simply scientific curiosities, exhibiting great technical skill on the part of their manufacturers, but were given little cultural significance. 


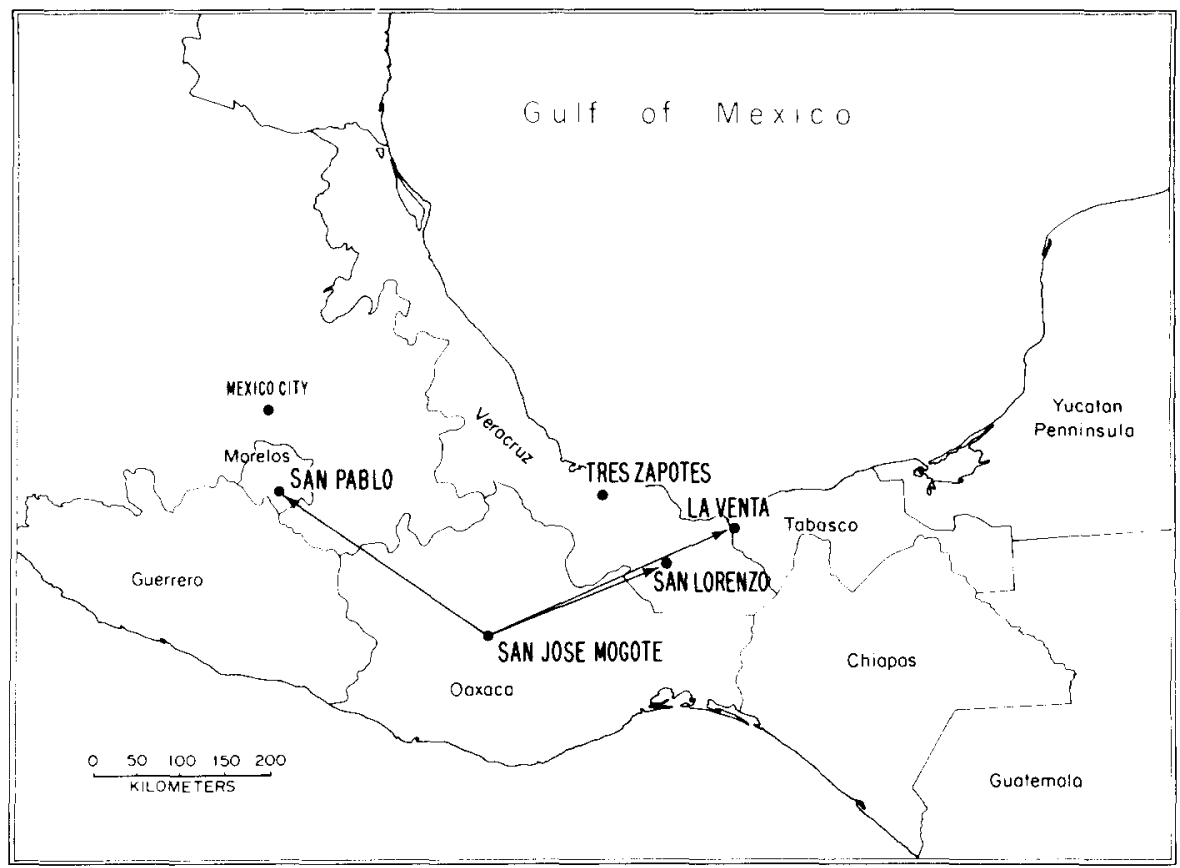

Fig. 1. Early Formative sites in Mesoamerica considered in this study. Arrows indicate sites linked by the exchange of iron ore mirrors as determined by magnetic properties.

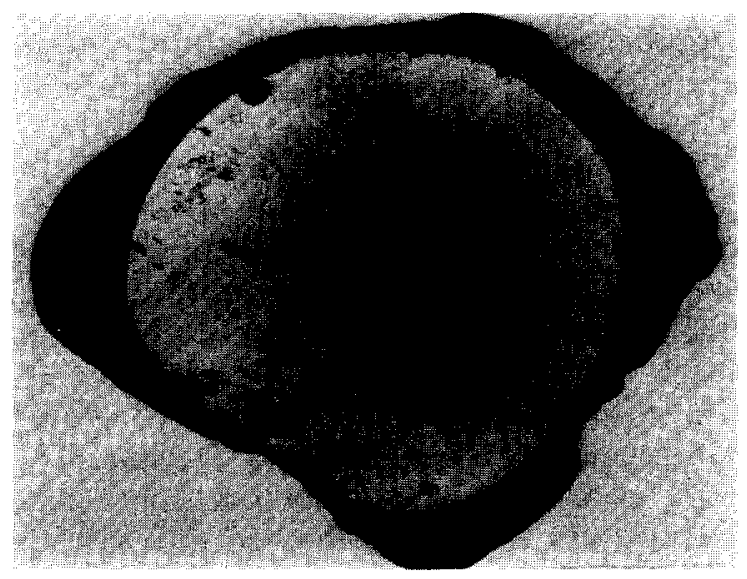

Fig. 2. Large, concave mirror from La Venta. Note drilled holes. It consists of an ilmenite iron ore, cf. fig. 7.

There were many unsubstantiated speculations as to their use. One small figurine wearing a tiny plaque of iron oxide ore was found at La Venta (fig. 3) and if this figurine bore some relationship to living Olmecs, as is almost certainly the case, the use of these iron ore mirrors as body adornments is more than a possibility. The holes drilled in them certainly indicate their

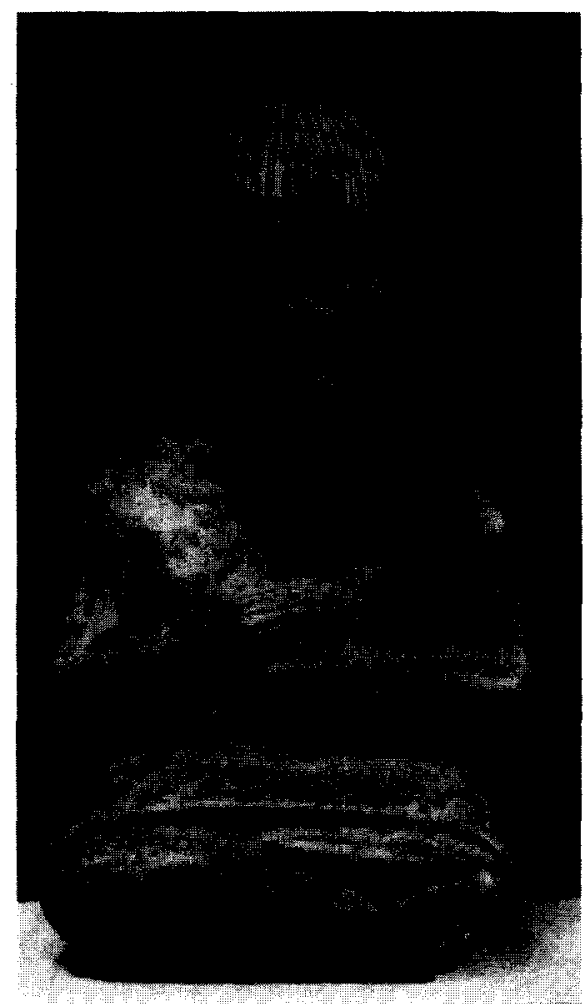

Fig. 3. Jade figurine from La Venta with a small, flat iron ore mirror on its chest. 
being suspended from some support by small cords.

Indications of the true significance of these iron ore artifacts were first put forward by Flannery and co-workers [4] in their excavation of Early Formative (1000-800 B.C.) villages in the Valley of Oaxaca (cf. fig. 1) and by investigations of Coe at the contemporaneous site of San Lorenzo in Veracruz (cf. fig. 1). In these investigations polished iron ore artifacts of nearly identical style, i.e. small, "thumbnail" in size and resembling those on the figurine in fig. 3 , were found at both of these sites which are separated by a distance of approximately $200 \mathrm{~km}$. From a much broader perspective than is relevant to this study, Flannery suggested that these iron ore artifacts were part of an exchange network between the Valley of Oaxaca and the Gulf Coast Olmec villages. Of equal importance was his additional suggestion that these iron ore artifacts were indeed body adornments reserved
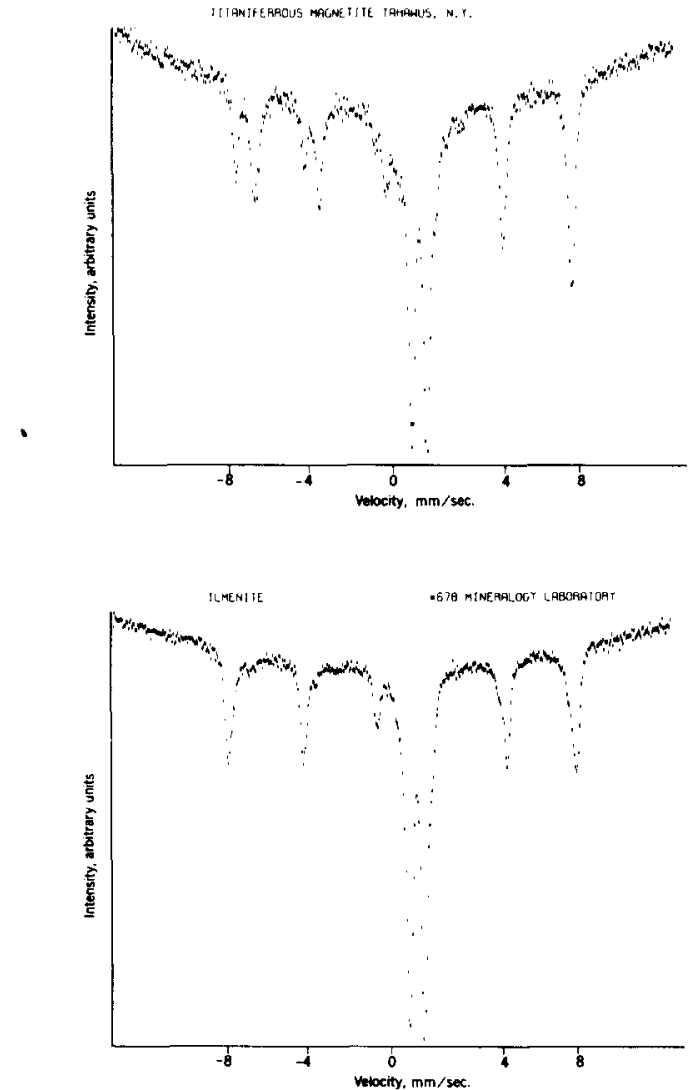

for societal elites.

At the early formative site of San Jose Mogote in the Valley of Oaxaca (cf. fig. 1), more than 500 pieces of iron oxide ore were found in an area of $10^{4} \mathrm{~m}^{2}$. Some of the ore fragments showed signs of having been worked, e.g. shaped and ground [5]. The strata on which San Jose Mogote lay does not contain iron ores. Still further, within the site of San Jose Mogote the iron ore fragments are confined to a single mirror-making residential ward. Worked, unworked, and finished mirrors were among the iron ore fragments, with the finished mirrors being rather rare. Other exotic materials, i.e. pearl oyster and fresh water mussel shells [6], were also found in association with the iron ore artifacts. It is noteworthy that San Jose Mogote was the largest village in the Valley of Oaxaca during Early Formative times.

In spite of the close proximity of iron ore sources to the Early Formative villages in the
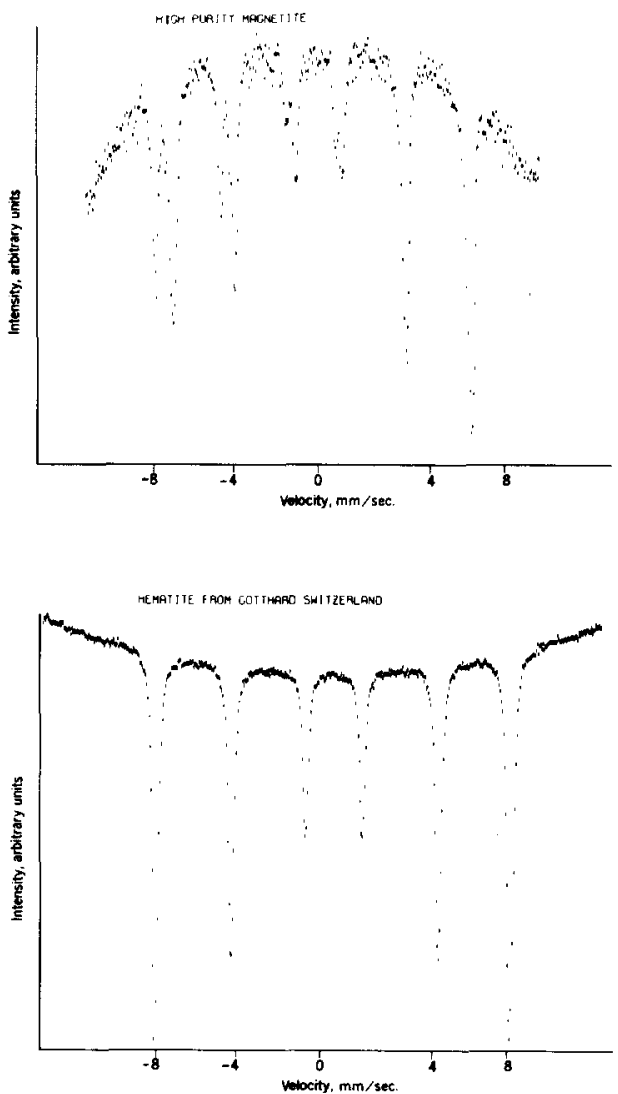

Fig. 4. ${ }^{57} \mathrm{Fe}$ Mössbauer spectra at $298 \mathrm{~K}$ of various types of naturally-occurring iron oxides. Upper left, titaniferrous magnetite from New York, USA. Upper right, high purity magnetite. Lower left, ilmenite (with some hematite). Lower right, hematite from Switzerland. 
Valley of Oaxaca, significant concentration of iron ore occurs only at San Jose Mogote; none was found at Huitzo, for example, and only one ore lump has been found at San Bartolo Coyotepec and Tieras Largas. Extensive reconnaissance by Flannery of other archaeological sites in Mesoamerica has failed to turn up evidence of extensive iron-ore workings outside of the Valley of Oaxaca. It was concluded, therefore, that iron ore deposits and workshops in Oaxaca were the source of the olmec, iron ore mirrors.

It is noteworthy that finished mirrors are extremely rare in the smaller villages of Oaxaca and are relatively plentiful in the larger cultural centers on the Gulf Coast. Thus, magnetic oxides were perhaps as much of an exotic material and as restricted to highly developed population centers in Early Formative Mesoamerica as in our present day societythough perhaps for entirely different reasons. Flannery [5] has suggested that these iron ore mirrors probably functioned as insignias of status. That is to say, the possession of these exotic materials did not have any intrinsic value in the conferring of status but served only to symbolize status ascribed at birth, such as exists among hereditary nobles. Such a function is at least consistent with the distribution pattern of these mirrors.

Of course, the above conclusions as to the function of these mirrors is mere speculation if it cannot be shown that the iron ore artifacts at La Venta and San Lorenzo are indeed the same composition as those in San Jose Mogote and are simultaneously the same as one or more of the iron ore deposites in Oaxaca. The chemical method usually employed in archaeological studies, such as X-ray fluorescence, electron microprobe, neutron activation and atomic absorption failed to demonstrate, however, any correlation between the artifacts at different sites in Mesoamerica or any similarities in compositions between the ore deposits and the artifacts. The difficulties of using chemical methods in sourcing studies have been pointed out recently [7] and it is possible that not only was there a loss of information associated with the simple binary and ternary plots normally employed but also that the variations in compositions were to subtle to distinguish either the artifacts or ore deposits themselves from one another. Also, too little is known about the systematics of trace elements in iron oxide ores to permit correlations among trace elements.

\section{Experimental}

As indicated earlier, the principal iron minerals in the mirrors were hematite, magnetite and ilmenite and as indicated in fig. 4, these three minerals give easily distinguishable ${ }^{57} \mathrm{Fe}$ Mössbauer spectra. Thus if the relative amounts of the minerals varied significantly from one ore source to another, artifacts derived from different ore sources would be easily distinguishable. Furthermore, the ${ }^{57} \mathrm{Fe}$ Mössbauer spectrum of each of the individual minerals is also sensitive to intracrystalline composition variations and the details of the spectra of each iron oxide phase can be used to further distinguish different ore deposits (and artifacts derived therefrom) from each other.

The advantage of the Mössbauer effect in this particular study is the fact that one obtains in a single measurement information on the number of phases present and their relative amounts, indirect information on intra-crystalline chemical composition and magnetic and crystal structures. Degeneracies in the chemical compositions of two or more specimens are not likely to be accompanied by simultaneous degeneracies in the number of phases present, the amounts of each phase present and their magnetic and crystal structures.

For most samples transmission Mössbauer spectra were obtained by means of an electromechanical velocity transducer operated in conjunction with a multichannel analyzer. The Mössbauer spectra of the bar-shaped artifact and one of the concave mirrors were obtained using a scattering geometry and a commercially available backscatter detector. $25 \mathrm{mCi}{ }^{57} \mathrm{Co} / \mathrm{Rh}$ or ${ }^{57} \mathrm{Co} / \mathrm{Cu}$ were employed as sources.

Samples of less than $12 \mathrm{mg}$ were scraped from the archaeological artifacts and geological iron ore specimens and were used in obtaining the transmission Mössbauer spectra. The resulting small absorber diameters $(\sim 3 \mathrm{~mm})$ and the strong collimation of the source produced an appreciable parabolic distortion in some of the spectra.

The technique for sampling the geological ore deposits has been described in detail by Pires- 
Ferreira [8]. The principal concern with the ore deposits relevant to this study is their homogeneity. Detailed measurements on five different samples from the Loma Los Sabinos and Loma de la Cañada Totomosle deposits indicated good homogeneity and the spectra of two typical samples from Loma Los Sabinos are shown in fig. 5 .

${ }^{57} \mathrm{Fe}$ Mössbauer spectra were obtained at $298 \mathrm{~K}$ for more than 50 ore samples from 43 deposits of which 36 were in the Valley of Oaxaca. Approximately 100 archaeological samples were also investigated. Obviously, only a synopsis of these data can be given here; but of the $\mathbf{4 3}$ ore samples only 5 exhibited Mössbauer spectra similar to those of the archaeological artifacts. In addition, 18 artifacts from San Jose Mogote were from the

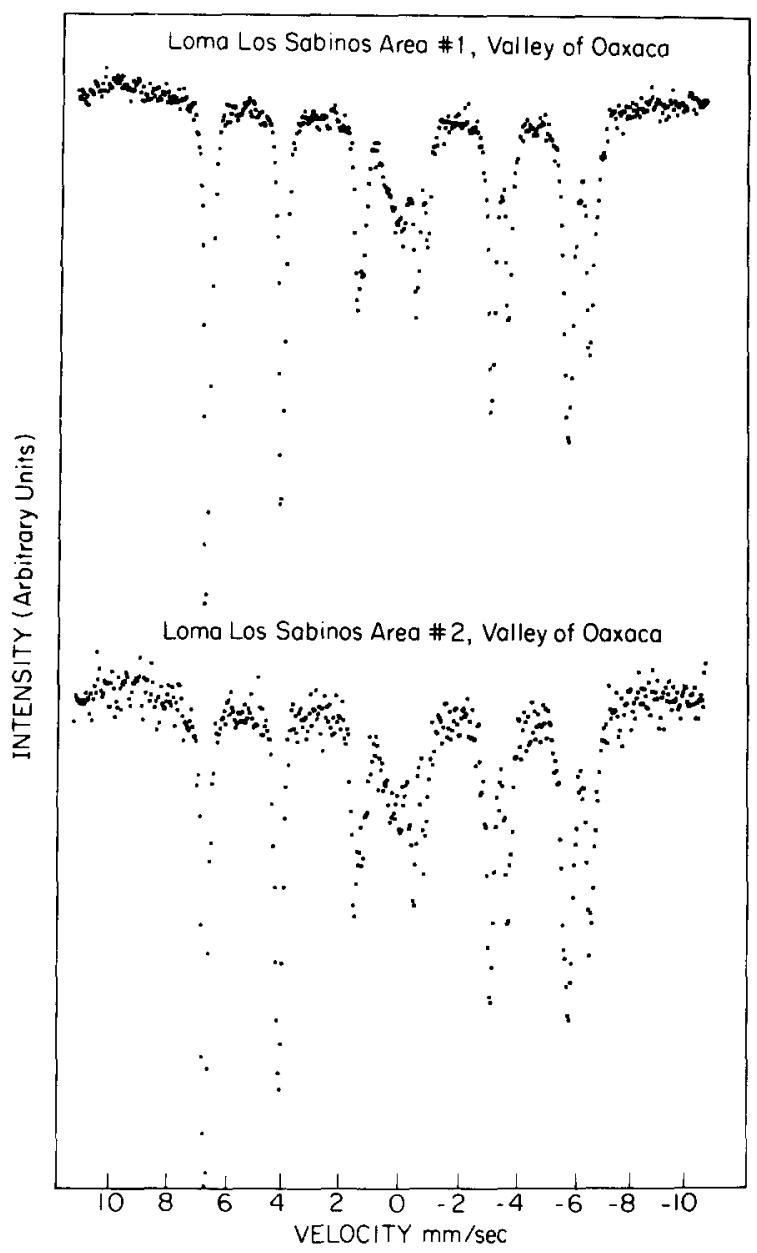

Fig. 5. ${ }^{57} \mathrm{Fe}$ Mössbauer spectra of iron ore samples from two different parts of the Loma Los Sabinos deposit. The two samples are virtually identical. high purity magnetite deposits at Loma de la Cañada Totomosle and Loma Los Sabinos.

\section{Results and discussion}

${ }^{57} \mathrm{Fe}$ Mössbauer spectra of iron ore from Loma de la Cañada Totomosle and archaeological artifacts from San Jose Mogote and San Pablo, Morelos are presented in fig. 6. It is noteworthy that San Pablo, Morelos is more than $320 \mathrm{~km}$ northeast of San Jose Mogote (cf. fig. 1). The Mössbauer spectra of these samples are identical and show them to consist of high purity magnetite. The Loma de la Cañada Totomosle ore was much preferred by the Early Formative artisans in San Jose Mogote since they apparently ignored many other iron ore
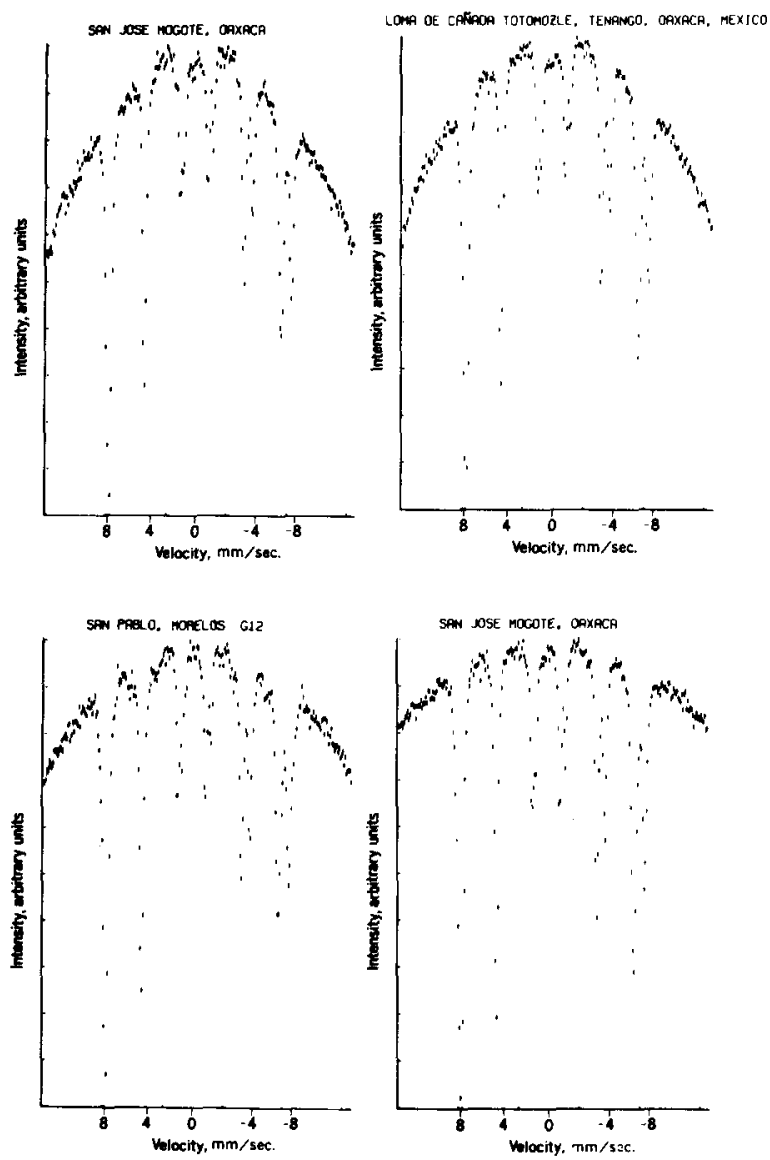

Fig. 6. ${ }^{57} \mathrm{Fe}$ Mössbauer spectra of an iron ore sample, upper right, and archaeological iron ore artifacts from two widely separated sites in the Valley of Oaxaca and the state of Morelos. The similarities in the spectra indicate a common origin. 
sources along the $30 \mathrm{~km}$ route to Loma de la Cañada Totomosle. As no other ore body in the Valley of Oaxaca has been found to consist almost entirely of high purity ( $>95 \%)$ magnetite, it is reasonably certain that the archaeological sample at San Pablo, Morelos has its origin in

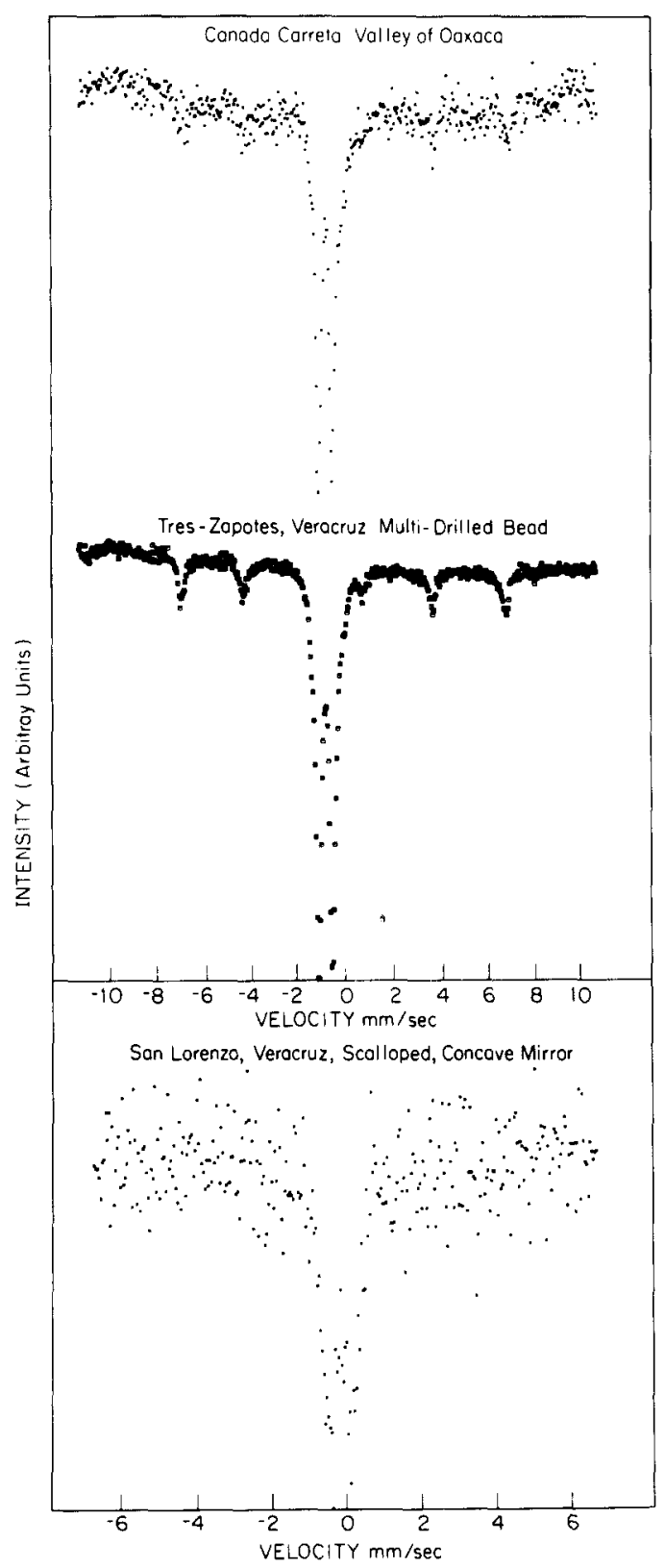

Fig. 7. Comparison of the ${ }^{57} \mathrm{Fe}$ Mössbauer spectra of an ore sample from the Valley of Oaxaca, top, a multi-drilled iron ore bead from Treas Zapotes in the Gulf Coast region, middle, and a concave mirror from the Gulf Coast site of San Lorenzo, all exhibiting very similar spectra. The ore is ilmenite, cf. fig. 4 . the iron ore "mirror" works of San Jose Mogote.

In fig. 7 spectra of an ore sample from the Cañada Carreta deposit and archaeological samples from Gulf Coast sites are presented. Again, the spectra are quite similar. In fact, all of the La Venta concave mirrors, except one, had spectra identical to those in fig. 7 , clearly indicating their origin in the Valley of Oaxaca. Further evidence connecting the La Venta concave mirrors to the Cañada Carreta deposit is the suggestion that the rear surface of the La Venta concave mirrors have the appearance of stream-rounded boulders [3]. The Cañada Carreta source is located very near a stream that contain within $800 \mathrm{~m}$ of the deposit, itself, iron ore fragments suitable for the production of the La Venta concave mirrors.

As the transmission Mössbauer measurements were being completed, the bar-shaped artifact, shown in fig. 8 , became available to us. This artifact was found in San Lorenzo in strata dated between 1400 and 1000 B.C. and has been referred to as a lodestone or magnetite compass [9]. It has been reported that this bar aligns its long axis approximately parallel to magnetic North if allowed to float freely in a heavy liquid or in water if supported by a material such as cork. Actually, the bar aligns it long axis $35^{\circ}$ west of magnetic North.

Even though it is not likely that this bar could have been part of a compass, it is known that many olmec sites contained earth mounds or platforms that were oriented $8^{\circ}$ west of magnetic North. The orientation of these structures is believed to have been accomplished by astronomical means but it is highly likely that this

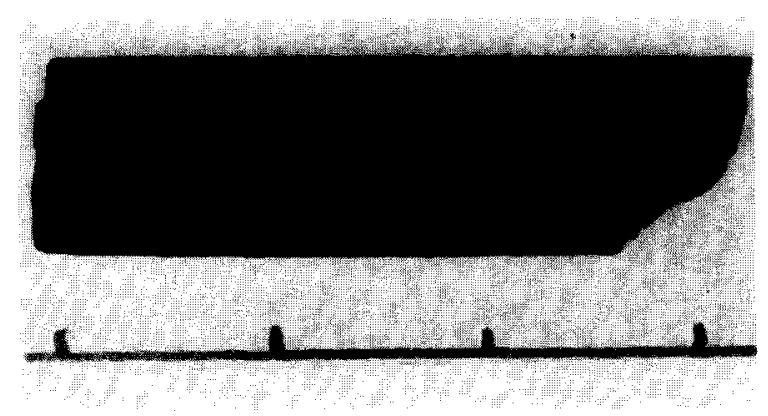

Fig. 8. Bar-shaped iron ore artifact discovered in strata dated 1400-1000 B.C. at the site of San Lorenzo and exhibiting a strong remanent magnetization parallel to its long axis. The scale divisions are in $\mathrm{cm}$. 
bar-shaped artifact could have been used in some instances as a local orienting device with the groove serving as a sighting line. A more complete discussion of this possibility has been presented by Carlson [9].

${ }^{57} \mathrm{Fe}$ Mössbauer backscatter measurements were made on this artifact to determine the carrier of the magnetic remanence, the ore deposit from which the material was obtained, and the direction of the remanence, if possible. The spectra shown in fig. 9 demonstrate that this artifact is composed of high purity hematite and not magnetite. The fact that lines 2 and 5 are more intense than lines 1 and 6 also indicates that the resultant spin moment is parallel to the grooved surface, i.e. lies in the "horizontal" plane. The resultant moment is not parallel to the narrow surface, however, as is obvious from

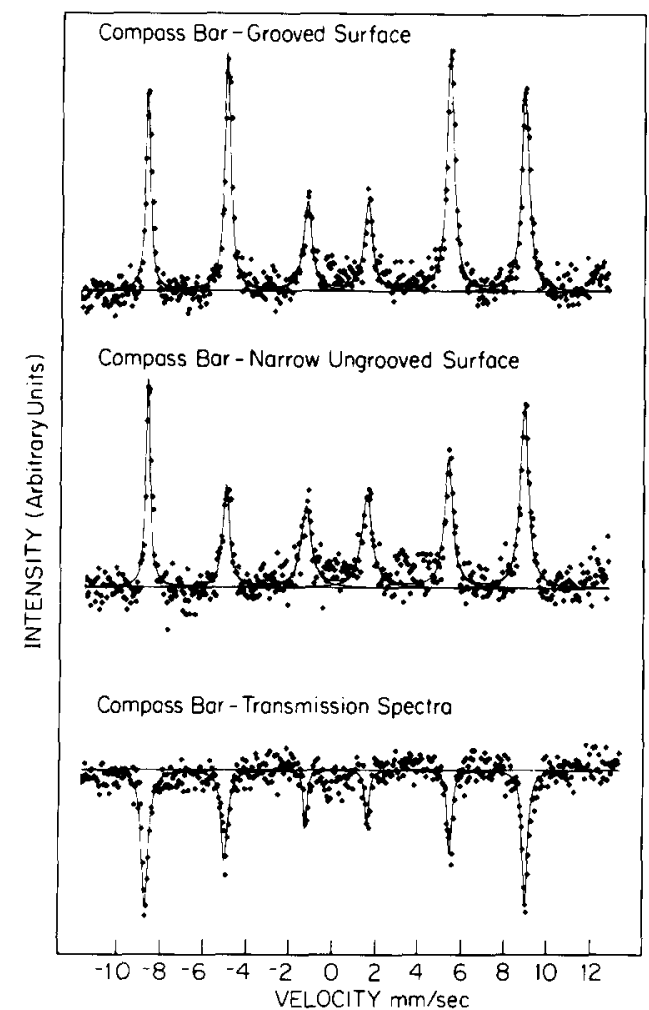

Fig. 9. ${ }^{97} \mathrm{Fe}$ Mössbauer backscatter spectra of the two surfaces shown in fig. 8 and a transmission spectrum of a powdered sample. The stronger intensity of lines 2 and 5 in the top spectra confirms the remanence of the entire bar. The iron ore is hematite (cf. fig. 4) and the identity of the line positions in the transmissions and backscatter spectra indicate hematite to be the major iron oxide in the bulk. Hematite is not, however, the primary carrier of the remanence, see text. the middle spectra in fig. 9; but the groove is also not parallel to the narrow surface.

Massive hematite of this purity, however, is not expected to have a remanent magnetization of sufficient strength to align an object of this size in the earth's magnetic field. Subsequent electron microprobe measurements revealed the presence of $\mathrm{Fe}_{2-x} \mathrm{Ti}_{x} \mathrm{O}_{3}$ lamellae with $x \cong 0.1$; and this is the phase that is primarily responsible for the strong remanence of this artifact. On the basis of the electron microprobe measurements, it is estimated that about $10 \%$ of the mass of this bar is the above mentioned irontitanium-oxygen phase. This finding is in good agreement with a recently published report on the origin of the remanence in lodestone [10]. Because of the strong similarities in their Mössbauer spectra, it is not possible to detect the presence of $10 \mathrm{wt} . \% \mathrm{Fe}_{2-x} \mathrm{Ti}_{x} \mathrm{O}_{3}$ with $x \cong 0.1$ in $\mathrm{Fe}_{2} \mathrm{O}_{3}$.

Because the backscatter spectra are surface sensitive, it is important to demonstrate that these spectra are characteristic of the bulk material. Therefore, the ${ }^{57} \mathrm{Fe}$ transmission spectrum of a $12 \mathrm{mg}$ sample removed from the end of the bar in fig. 8 is also shown in fig. 9. The identity of the line positions and shapes with those in the backscatter spectra shows that the bar artifact does indeed consist of high purity hematite and that the magnetic remanence is a property of the artifact since the $3: 2: 1: 1: 2: 3$ intensity ratios of the lines are characteristic of a random magnetization vector in the powdered material.

Fig. 10 contains the ${ }^{57} \mathrm{Fe}$ Mössbauer backscatter spectra of a concave mirror similar to that in fig. 2 obtained in the Mexican state of Guerrero. This material exhibited no magnetic remanence and none is revealed in the backscatter spectra. The intensities of the lines are in the ratios $3: 2: 1: 1: 2: 3$. The nondestructive aspect of this method of analysis stands out in this instance since these highly polished mirrors cannot be subjected to any damage and the removal of small, $10-20 \mathrm{mg}$ samples cannot be relied upon to always give a good measure of bulk composition for such large artifacts. It is to be noted especially, though, that the method of analysis is intrinsically magnetic, depending on the number of magnetic sublattices, the Curie temperature, the magnetic moment and the effects of chemical composition on each of 

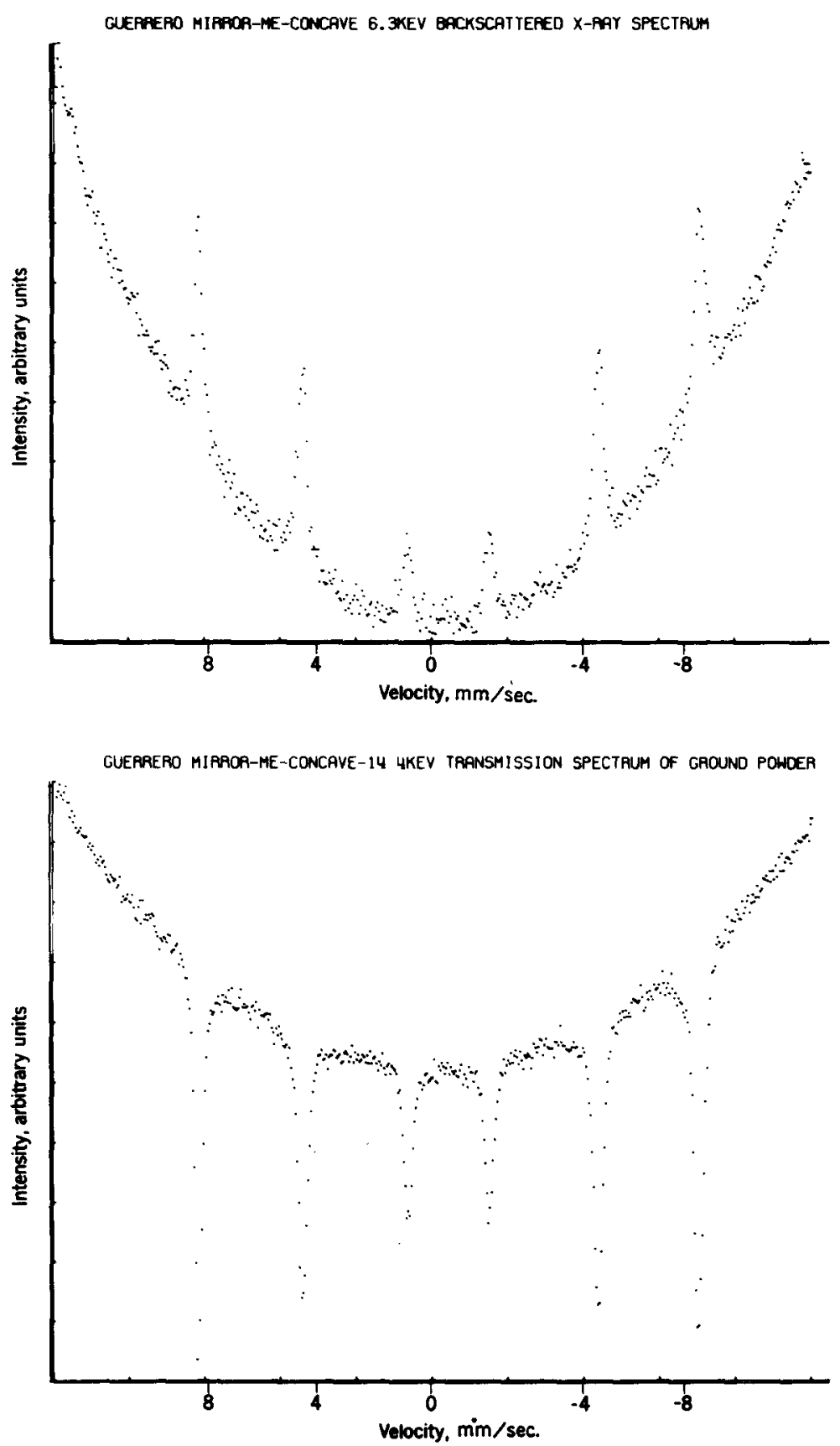

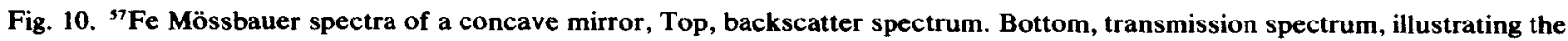
reliability of the backscatter technique for sampling bulk properties. The iron ore is hematite.

these as monitored by the magnetic hyperfine field at the nucleus of the iron atom.

\section{Conclusion}

Magnetic oxides were among the exotic materials of Formative Mesoamerica. In con- trast to the world of today, their function was primarily non-utilitarian and they were used principally as body adornments. It is probable, however, that a small number of iron ore artifacts were used in esoteric architectural or geomantic applications. If the unusual bar-like artifact with the strong magnetic remanence 
should prove to be part of a direction finding device, this device would predate the discovery of the compass by the Chinese by more than a millennium. Even in Formative Mesoamerica, however, magnetic oxides were associated with large population centers and restricted to the cultural elite. In this regard magnetic oxides in Formative Mesoamerica were not unlike magnetic oxides in the world of today. The daily lives of the general populace were greatly influenced by magnetic oxides but most persons probably had little appreciation for this fact.

\section{References}

[1] I. S. Jacobs, J. Appl. Phys. 40 (1969) 917.

[2] M. Coe, America's First Civilization (American Heri- tage, New York, 1968).

[3] P. Drucker, R. Heizer and R. Squier, Bur. Amer. Ethnol. Bull. 170 (1955).

[4] K.V. Flannery (Ed.), The Early Mesoamerican Village (Academic Press, New York, 1976).

[5] K.V. Flannery, in: Dumbarton Oaks Conference on the Olmec, E. Benson (Ed.) (Dumbarton Oaks, Washington, 1968) p. 79.

[6] J. Pires-Ferreira, Memoirs of the Museums of Anthropology (University of Michigan, Ann Arbor, 1975).

[7] G.K. Ward, Archaeometry 16 (1974) 41.

[8] J. Pieres-Ferreira, Ph.D. Thesis, University of Michigan, U.S.A. (1973).

[9] J.B. Carlson, Science 189 (1975) 753.

[10] P. Wasilewski, Rept. X-691-76-110, NASA Goddard Space Flight Center, Greenbelt, MD., USA (1976). 